\title{
How ecumenical expressivism confuses the trivial and the
}

\section{substantive}

\section{ANDREAS L. MOGENSEN}

1.

According to ecumenical expressivism, a normative judgment is a hybrid state comprising both a desire-like attitude and a corresponding belief. For example, on what Ridge (2007) calls Plain Vanilla ecumenical expressivism (PVEE), the normative judgment that $\phi$-ing is right consists in (1) a non-cognitive state of approval of actions insofar as they have a certain property, and (2) the belief that $\phi$-ing has that property.

On this view, the property that guides a person's approval is an ordinary descriptive property whose identity varies according to one's sensibility. A utilitarian might approve of actions insofar as they maximize utility. In that case, she judges an act to be right only when she believes the action exhibits that property. A Kantian might approve of actions insofar as their maxims can be willed as universal laws. In that case, she judges an act to be right only when she believes the action exemplifies this property.

As Ridge (2015: 475-76) emphasizes, the belief-component of a normative judgment involves a mental demonstrative as opposed to a de dicto specification of the relevant property that governs the person's attitudes. Thus, when I form a normative judgment, the component belief that partially constitutes that judgment will be a belief to the effect that the action has that property, where that property refers to whatever property in fact elicits my approval, be it utility-maximization or universalizability. I need not know the nature of the property in question. After all, most people don't have a very clear sense of what criteria they take to define right and wrong. 
It is also worth emphasizing that ecumenical expressivism does not ask us to think of normative judgments as involving beliefs that represent actions as instantiating the normative property rightness. In this respect, ecumenical expressivism differs crucially from the ecumenical cognitivism proposed by philosophers like Copp (2001). More generally, ecumenical expressivism treats the non-cognitive state involved in making a normative judgment as primary and the belief as secondary. The content of the belief - in particular, that of its demonstrative component - is determined by the person's non-cognitive attitude. And, unlike on the ecumenical cognitivist view, the truth-condition of the believed content is not the truth-condition of the judgment of which it is a part. On this view, as on traditional expressivist views, it is the primary function of our normative judgments to take up a certain practical stance toward the world, and not to represent the world as being a certain way.

Over and above a theory of normative judgment, ecumenical expressivism offers a theory of normative language. Its core meta-semantic commitment is that normative utterances express hybrid states of the kind just described and have their semantic content determined in virtue of the kind of state they are used to express. Thus, according to Ridge (2014: 195-96), utterance of ' $\phi$-ing is right' expresses that the speaker is in some suitable combination of attitudes such that she judges that $\phi$-ing is right.

In order to solve the Frege-Geach problem, ecumenical expressivism asks us to suppose that the logical structure of any given normative judgment (and its associated utterance) is to be mirrored by the logical structure of the believed proposition. For example, on PVEE we say that an utterance of 'If $\phi$-ing is right, then $\psi$-ing is right' expresses the normative judgment If $\phi$-ing is right, then $\psi$-ing is right, which consists in (1) a non-cognitive state of approval of actions insofar as they have a certain property, and (2) the belief that if $\phi$ ing has that property, then $\psi$-ing also has that property. This procedure for interpreting logically complex judgments and utterances can be generalized quite straightforwardly to 
account for negation, disjunction, conjunction, etc. and appears to explain the inferencelicensing and consistency properties we perceive in normative thought and language (Ridge 2006: 324-30, 2007: 62-67, 2014: ch. 5).

Overall, ecumenical expressivism seems to be a promising theory of normative thought and language with many advantages over traditional expressivist theories. ${ }^{1}$ But it is not without problems.

2.

Working within the framework of PVEE, the problem I mean to raise arises as follows. The theory implies that when someone forms a normative judgment about what is right, this judgment is partially constituted by a belief whose content is similarly specified except that where the content of the judgment is specified using is right, we are to replace these occurrences with has that property, with these instances all having the same content and referring to that property in virtue of which the agent approves of actions. What happens, then, when someone makes a normative judgment involving that same demonstrative? What happens if I form an opinion about the normative significance of an action having that property?

Suppose, for example, that the property of actions that elicits my approval is utilitymaximization. Suppose I judge that an act is right iff it has that property. PVEE entails that we should understand me in that case as instantiating the following hybrid state: (1) a noncognitive attitude of approval of actions insofar as they have a certain property (utilitymaximization), (2) the belief that an act has that property iff it has that property.

\footnotetext{
${ }^{1}$ See, e.g., Ridge (2014: 166-67) on the 'wishful thinking' problem due to Dorr (2002), and Ridge (2014: ch. 7) on accommodating normative truth without deflationism.
} 
It is perhaps a little odd that the theory seems to entail that this judgment is partially constituted by belief in a trivial proposition. Setting aside that issue, let's consider how we should understand my state of mind if I instead make a straightforwardly tautological judgment. Suppose I judge that an act is right iff it is right. Here, the theory implies that I instantiate the following hybrid state: (1) a non-cognitive attitude of approval of actions insofar as they have a certain property (utility-maximization), (2) the belief that an act has that property iff it has that property. Notably, this is exactly the same hybrid state as before.

According to PVEE, then, when I approve of actions insofar as they have a certain property, there is no difference in respect of my attitudes when judging that an act is right iff it has that property and judging that an act is right iff it is right. But this seems quite implausible. Quite apart from its surface counter-intuitiveness, we can note that any rational person who approves of actions insofar as they have a certain property would be less confident in judging that an act is right iff it has that property than in judging that an act is right iff it is right, whereas this seems impossible to explain if the attitudes involved are the same in each case: any greater degree of intensity in respect of either constituent attitude would be mirrored across both judgments. ${ }^{2}{ }^{3}$ Thus, any plausible hybrid theory of normative

\footnotetext{
${ }^{2}$ For a related worry about ecumenical expressivism and fundamental normative uncertainty, see Bykvist and Olson (2009).

${ }^{3}$ This need not embarrass the ecumenical expressivist if they elect to violate the intuitive expectation, preserved in the theory of normative certitude proposed by Ridge $(2003,2007)$, that one's confidence in respect of some normative judgment depends on properties of its constituent attitudes in such a way that one's credence in one judgment cannot differ from one's credence in another (at a given time) unless these differ in respect of their constituent attitudes. Sadly, I don't have space within this paper to fully investigate the plausibility of violating this intuitive expectation. I am pre-theoretically sceptical of the proposal, and I believe the onus would be on defenders of ecumenical expressivism to develop it into a plausible theory of normative certitude.
} 
judgment should not count me as entering into exactly the same state of mind when making these judgments. The problem is that ecumenical expressivism apparently does exactly that. ${ }^{4}$

3.

Here is one possible reply to the argument of the previous section. We may suppose that one and the same thought can differ in cognitive significance according to its mode of presentation. For example, a theory on which the content of a predicate is the property it expresses will count the belief that a liquid is water iff it is $\mathrm{H}_{2} \mathrm{O}$ and the belief that a liquid is water iff it is water as having the same content. To account for the obvious difference in cognitive significance, we may insist that the content has a different mode of presentation in each case. Could the ecumenical expressivist try to accommodate the point for which I've argued by supposing that something analogous holds with respect to the judgments that concern us: i.e., that these involve the same content, but under different modes of presentation?

It would be easy enough to posit this kind of difference if the beliefs that partially constitute these judgments differed in their Kaplanian characters. Consider the case where a utilitarian agent judges that an act is right iff it is right and also that an act is right iff it maximizes utility. On PVEE, this individual approves of actions that maximize utility and believes that an act has that property iff it has that property, as well as that an act has that property iff it maximizes utility. Since has that property and maximizes utility have the same content but different characters, the same holds of the constituent beliefs.

\footnotetext{
${ }^{4}$ There is an obvious similarity between the problem raised here and the Open Question Argument (Moore 1903), which may also suggest a link to the 'paradox of analysis' (Fumerton 1983). Notably, Ridge (2014: 7176) is sympathetic to the Open Question Argument, taking it to support expressivism.
} 
The problem is that nothing like this holds for the judgments that concern us. The constituent beliefs here clearly have the same content and character. In each case, the constituent belief is that an act has that property iff it has that property, where has that property has the same character and content in each instance. Therefore, it seems there is no basis on which to derive a difference in mode of presentation between the two judgments so long as these are analysed in accordance with PVEE.

4.

It may be argued in a different way that PVEE has the resources to distinguish between these judgments. Consider again the case in which I have (1) a non-cognitive attitude of approval of actions insofar as they have a certain property (utility-maximization), (2) the belief that an act has that property iff it has that property. We might suppose that the ecumenical expressivist can count me as making two distinct judgments here: one trivial, the other substantive. She merely has to say that although these judgments are distinct in respect of identity, they are realized by the same underlying hybrid state, much as a statue and a lump of clay may be thought of as two non-identical objects constituted by the same underlying matter. And just as we might think that the statue and the lump can be seen to be distinct in virtue of exhibiting different modal properties (for example, only the statue can survive the replacement of its component parts by other materials), so the two judgments in question may be seen to be distinct because they exhibit distinct modal properties according to the theory. In particular, one might argue, ecumenical expressivism allows us to say that the trivial judgment can survive the agent's switch of allegiance to Kantianism, whereas the substantive judgment cannot.

This last point is worth explaining in detail. In order to count as judging that an act is right iff it is right, an individual must instantiate some combination of attitudes such that she 
approves of actions insofar as they have some property and believes that an act has that property iff it has that property. But there are obviously many different ways in which to realize this combination of attitudes. A Kantian may token this judgment-type when she approves of actions insofar as their maxims can be willed as universal laws and believes that an act has this property iff it has this property. In making this judgment, she would not also be judging that an act is right iff it has that property, where that property picks out the property that guides $m y$ attitudes of approval: i.e., utility-maximization. She clearly does not instantiate the right hybrid state to count as making this judgment according to ecumenical expressivism. ${ }^{5}$ Because the trivial judgment is multiply realizable in this way, it follows that if my sensibility were to switch so that the property that elicits my approval were maximuniversalizability rather than utility-maximization, then I could still maintain the same trivial judgment, ${ }^{6}$ whereas I would not continue to endorse the substantive judgment that I previously accepted. Hence, these judgments are not one and the same, even if both are now constituted by the same pair of attitudes: the one can survive changes in attitude that the other cannot.

For all that has been said, it remains the case that if my approval is elicited by the property of utility-maximization, PVEE entails that in endorsing the substantive judgment that an act is right iff it has that property, I also thereby endorse the trivial judgment that an act is right iff it is right - and vice versa. To endorse the one is ipso facto to endorse the other,

\footnotetext{
${ }^{5}$ She would, of course, instantiate the right hybrid state to count as judging that an act is right iff it has that property, where that property refers to the property that guides her attitudes of approval: i.e., maximuniversalizability.

${ }^{6}$ Some may doubt that I should be counted as maintaining one and the same numerically identical judgment as opposed to successively exhibiting two numerically distinct tokens of the same judgment-type, but for the sake of argument I am happy to grant that the former is the correct description.
} 
since acceptance of either is realized via instantiation of one and the same hybrid state. As I see it, to suggest that this hybrid state gives rise to two distinct judgements is to re-state the problem, not to solve it. The objection is that the theory should not count my making these judgments as involving exactly the same attitudes, because what it is to endorse the trivial thought is surely something quite distinct from what it is to endorse the substantive principle.

To add to the considerations already mentioned, notice that if we consider the grounds on which a person would typically come to endorse these verdicts, we find that they are very different. Thus, suppose I have not yet endorsed either. The considerations by which I might become convinced of the trivial thought that an act is right iff it is right will confer little if any support on any substantive normative judgment. I would endorse the trivial thought by recognizing it as a logical truth, whereas I take it that merely logical considerations do not support any substantive normative judgment. To endorse a substantive principle of right action on the basis of merely logical considerations would be unjustified. But apparently this cannot be avoided, unless I also want to withhold judgment from the trivial principle that an act is right iff it is right, because if I endorse this judgment on the basis of merely logical considerations, I ipso facto endorse the substantive judgment. It is hard to believe that I must really face this absurd dilemma, torn between withholding belief from a trivial logical truth and endorsing a substantive normative judgment without sufficient justification. The considerations rehearsed in this section do not allow the theory to avoid this implication, I think, nor do they make it any easier to accept.

5.

PVEE is not the only possible formulation of the theory. Alternative interpretations have been suggested, including an Ideal Advisor version (Ridge 2007, 2009) and a Standards-Based version (Ridge 2014). According to the former, the normative judgment $\phi$-ing is right consists 
in (1) a non-cognitive state of approval of actions insofar as they would be recommended by a certain kind of ideal advisor, and (2) the belief that $\phi$-ing would be recommended by that kind of advisor. The Standards-Based version of ecumenical expressivism is the most recent edition of the theory and implies that the normative judgment $\phi$-ing is right consists in (1) a non-cognitive state consisting in a normative perspective whose criteria exclude certain standards for practical reasoning, and (2) the belief that $\phi$-ing would be recommended by any ultimate standard of practical reasoning not ruled out by those criteria.

Each view is otherwise similar to PVEE. Thus, on neither view must we all share the same sensibility. A utilitarian may approve of actions insofar as they would be recommended by a utilitarian saint or have a normative perspective that rules out any ultimate standard of practical reasoning other than utilitarianism. Obviously, a Kantian would not. The FregeGeach problem is also solved in the same way, by insisting that the logical structure of any given normative judgment is suitably mirrored by the logical structure of the believed proposition. On the Ideal Advisor version, the logical structure is mirrored by beliefs in which is right is replaced by would be recommended by that kind of advisor, where that kind of advisor picks out whichever type of advisor is such that her recommendations guide the individual's attitudes of approval. On the Standard-Based version, the logical structure is mirrored by beliefs in which is right is replaced by would be recommended by any ultimate standard of practical reasoning not ruled out by those criteria, where those criteria pick out the criteria implicit in the person's normative perspective.

In section 2, I set up the problem I wanted to raise using the Plain Vanilla interpretation of ecumenical expressivism, but it is straightforward to re-state the problem so as to apply to the Ideal Advisor and Standards-Based versions of the theory. Thus, suppose the former is true and that I approve of actions insofar as they would be recommended by a utilitarian saint. We will then end up running together the case in which I formulate the 
substantive judgment that an act is right iff it would be recommended by that kind of advisor and the very different case where I formulate the trivial judgment that an act is right iff it is right. Or suppose the latter version of the theory is true and that my normative perspective has criteria that exclude all standards for practical reasoning except utilitarianism. Then we will end up running together the case in which I formulate the substantive judgment that an act is right iff it would be recommended by any ultimate standard of practical reasoning not ruled out by those criteria and the quite different case in which I formulate the trivial judgment that an act is right iff it is right.

6.

Could any version of the ecumenical theory avoid confusing the trivial and the substantive in this way?

The problem I have noted seems to arise ultimately from the commitment that when someone forms a normative judgment about what is right, this judgment is partially constituted by a belief whose content is similarly specified except that where the content of the judgment is specified using right, we uniformly replace these occurrences with instances of some other concept, $F .^{7}$ Any theory with this sort of commitment will face the problem I have noted when we consider and compare judgments in which both right and $F$ occur together and judgments with the same logical structure in which right also occurs in place of $F^{8}$

\footnotetext{
${ }^{7}$ Where $F$ is a demonstrative, we must also specify that it is assumed to have the same content in each instance, assuming a fixed agent and a fixed non-cognitive sensibility.

${ }^{8}$ We could try to retain this commitment but avoid the problem I've noted by supposing that the agent's noncognitive attitude can vary across different normative judgments. But Schroeder (2009: 268-75) argues
} 
Ideally, then, the ecumenical expressivist should avoid this commitment. However, the proposed solution to the Frege-Geach problem offered to us by the ecumenical theory depends critically on interpreting the underlying belief involved in any given normative judgment via this substitution procedure. And it is difficult to see how the underlying belief can mirror the logical form of the judgment in any other fashion, at least if we are to preserve the underlying spirit of the solution and capture the inference-licensing and consistency properties of normative thought and language. We could, of course, refuse to substitute out occurrences of right, letting the underlying belief have a robust normative proposition as its content, but this would be to forego ecumenical expressivism in favour of ecumenical cognitivism. The only remaining options would appear to be as follows.

Firstly, we could try expanding the substitution procedure, as follows. We could say that when someone forms a normative judgment about what is right, this judgment is partially constituted by a belief whose content is similarly specified except that (i) where the content of the judgment is specified using right, we uniformly replace these occurrences with instances of $F$ in specifying the content of the belief and (ii) where the content of the judgment is specified using $F$, we uniformly replace these occurrences with instances of some other concept, $G$, in specifying the content of the belief. This would allow us to evade the problem noted above, allowing us to distinguish cases in which agent makes a judgment in which both right and $F$ occur together cases involving judgments with the same logical structure in which only right occurs. But the problem merely re-appears in a different form, as we will now run together cases in which the agent formulates a judgment in which both right and $F$ occur and

convincingly that any theory allowing for this faces significant difficulties in preserving the inference-licensing property of valid moral arguments. 
cases in which she formulates a judgment with the same logical structure in which $G$ occurs in the place of $F .^{9}$

The final option would be to insist that when someone forms a normative judgment about what is right, this judgment is partially constituted by a belief involving a concept that cannot occur (with the same content) as part of a normative judgment. Thus, we could say that whereas normative judgments are partially constituted by beliefs about which actions are $F$, no one is capable of forming normative judgments about which actions are $F$. In that case, we won't face the problem of distinguishing between endorsing judgments in which both right and $F$ occur together and endorsing judgments with the same logical structure in which only right occurs, since there would be no judgments of the former kind.

The problem, of course, is to make good on this hypothesis. This requires finding a suitable concept to play this sort of role and some plausible independent reason to suppose that a concept of this kind is involved in the beliefs that partially constitute our normative judgments. To my mind, no plausible candidate suggests itself as fitting this bill. Obviously, we should remember Dennett's Dictum: a failure of imagination is not an insight into necessity (Dennett 1991). But I believe the onus is on ecumenical expressivists to suggest a plausible candidate. Until such time as a plausible candidate is identified, I believe we should be sceptical that ecumenical expressivism can offer us a satisfactory theory of normative thought and language. ${ }^{10}$

\footnotetext{
${ }^{9}$ Obviously, we could continue kicking the can down the road, insisting that if $G$ occurs in the content of a judgment, the belief instead involves the concept $H$. But it is easy to see that the problem will keep re-emerging. ${ }^{10}$ I'm very grateful to Michael Ridge for detailed comments on prior drafts of this paper, which helped avoid some significant mistakes and confusions on my part. I'd also like to thank three anonymous referees at Analysis for their extremely helpful comments and criticisms.
} 
andreas.mogensen@philosophy.ox.ac.uk

\section{References}

Copp, D. 2001. Realist-expressivism: a neglected option for moral realism. Social Philosophy and Policy 18: 1-43.

Dennett, D. 1991. Consciousness Explained. Boston: Little, Brown and Company.

Dorr, C. 2002. Non-cognitivism and wishful thinking. Noûs 36: 97-103.

Bykvist, K. and Olson, J. 2009. Expressivism and moral certitude. The Philosophical Quarterly 59: 202-215.

Fumerton, R. 1983. The paradox of analysis. Philosophy and Phenomenological Research 42: 477-497.

Moore, G. E. 1903. Principia Ethica. Cambridge: Cambridge University Press.

Ridge, M. 2003. Certitude, importance, and robustness for non-cognitivists. Brown Electronic Article Review Service (BEARS),

<http://www.brown.edu/Departments/Philosophy/bears/0301ridg.html>

Ridge, M. 2006. Ecumenical expressivism: finessing Frege. Ethics 116: 302-336.

Ridge, M. 2007. Ecumenical expressivism: the best of both worlds? Oxford Studies in Metaethics 2: 51-76.

Ridge, M. 2009. The truth in ecumenical expressivism. In Reasons for action, eds. D. Sobel and S. Wall, 219-242. Cambridge: Cambridge University Press.

Ridge, M. 2014. Impassioned belief. Oxford: Oxford University Press. 
Ridge, M. 2015. Replies to critics. Analysis 75: 471-488.

Schroeder, M. 2009. Hybrid expressivism: virtues and vices. Ethics 119: 257-309. 